\title{
Modelos de séries temporais aplicados à previsão de Material Particulado (PM10) na Região da Grande Vitória/ES.
}

\author{
Barbosa, G.C. ; Nalli, S.F. ; Gripa, W.R. ${ }^{2}$ \\ 1 Faculdade do Centro Leste - UCL, Serra, ES, Brasil \\ 2 Departamento de Matemática, Centro Universitário Norte do Espírito Santo, São Mateus, ES, Brasil
}

\begin{abstract}
Resumo
Este estudo teve como objetivo modelar as concentrações de material particulado $\mathrm{PM}_{10}$ para realizar previsões no município de Serra, Região da Grande Vitória, Brasil, por meio dos modelos de séries temporais. Os dados de concentração do poluente foram obtidos por umas das redes de monitoramento da qualidade do ar localizado no bairro de Carapina no período de jan/2010 a Nov/2013. Inicialmente ajustou-se um modelo SARIMA $(1,1,2)(1,1,2) 7$ e comparou-se os valores previstos pelo modelo com as concentrações reais obtidas em dez/2013. Os resultados mostraram que o modelo Sazonal ARIMA prevê as concentrações de forma muito eficaz, sendo uma importante ferramenta para previsão da qualidade do ar para a região.

Palavras chaves: Séries temporais, Poluição do ar, Estatística, Sarima.
\end{abstract}

\section{Introdução}

A poluição do ar nos grandes centros urbanos tem registrado níveis cada vez menos seguros para a sua população, sendo tais efeitos nem sempre visíveis devido ao tamanho das partículas com inúmeras fontes de emissão tais como os meios de transporte, combustível fóssil e a atividade industrial que contribuem com grande parcela nas emissões.

A qualidade do ar urbano tem causado sérios problemas às condições de vida das pessoas, principalmente crianças e idosos, dois grupos susceptíveis aos efeitos da poluição atmosférica. Os efeitos adversos dos poluentes atmosféricos na saúde humana têm sido uma preocupação dos órgãos regulamentadores e de saúde de pública ao longo dos últimos 50 anos. Os efeitos nocivos da poluição têm sido observados no aumento da mortalidade e da morbidade por doenças respiratórias e cardiovasculares [1-4]. O objetivo deste estudo foi desenvolver modelos de séries temporais para predizer aas concentrações de material particulado $\mathrm{PM}_{10}$, na região de Carapina/Serra/ES/Brasil, no período compreendido entre 2010 a 2013.

\section{Materiais e métodos}

As séries diárias das concentrações de poluição do ar, para o período de janeiro de 2010 a dezembro de 2013, foram obtidos junto ao Instituto Estadual de Meio Ambiente e Recursos Hídricos (IEMA), que atualmente possui 8 estações automáticas de monitoramento da qualidade do ar na RGV (Região da Grande Vitória), sendo uma delas na região de Carapina/ES, região de abrangência do estudo. Para esses poluentes foi calculada a média aritmética diária sendo consideradas representativas. Medidas diárias de material particulado $\left(\mathrm{PM}_{10}\right)$ foram obtidas. Para o cálculo desses indicadores (município) todas as médias diárias do monitor localizado na presente região estavam disponíveis, sendo esses utilizados na modelagem estatística e representativos. Para todos os poluentes estudados no presente trabalho, a coleta de dados compreendeu um período de 24 horas, que se iniciava na primeira meia hora do dia.

\subsection{Modelo Sarima}

Diversas séries apresentam uma componente sazonal importante, sendo necessária a inclusão dessa componente no modelo. Os modelos ARIMA sazonais, conhecidos como SARIMA $(p, d, q) \times(P, D, Q)$ que pode ser escrita da forma:

$$
\Phi_{p}\left(B^{S}\right) \phi(B) \nabla_{s}^{D} \nabla^{d} Z_{t}=\alpha+\Theta_{Q}\left(B^{S}\right) \theta(B) a_{t}
$$

e denotado também por $\operatorname{ARIMA}(p, d, q) \times(P, D, Q) S$.

\section{Resultados}

Para que haja uma melhor compreensão do comportamento ao longo do tempo estudado dos dados, a Figura 1 apresenta as concentrações de $\mathrm{PM}_{10}$ distribuída entre os períodos de 2010 a 2013. Observa-se que a distribuição da série possui sazonalidade evidenciada ao longo do período estudado com média e desvio padrão respectivamente igual 


\section{Encontro Científico de Física Aplicada}

a 19,83 e 7,35 . Outro dado importante é de que nenhum valor coletado ultrapassou o limite critico de $150 \mu \mathrm{g} / \mathrm{m}^{3}$ estabelecido pelo CONAMA 99/03[1].



Figura 1: Série temporal das concentrações de material particulado PM10 na região de Carapina/ES/Brasil.

O modelo SARIMA $(1,1,2)(1,1,2) 7$, foi o que ajustou melhor ao conjunto de dados. O Ajuste do modelo mostra uma boa captura da variabilidade, bem como também a inclusão da tendência e sazonalidade do modelo como pode ser visualizado na Figura 2.

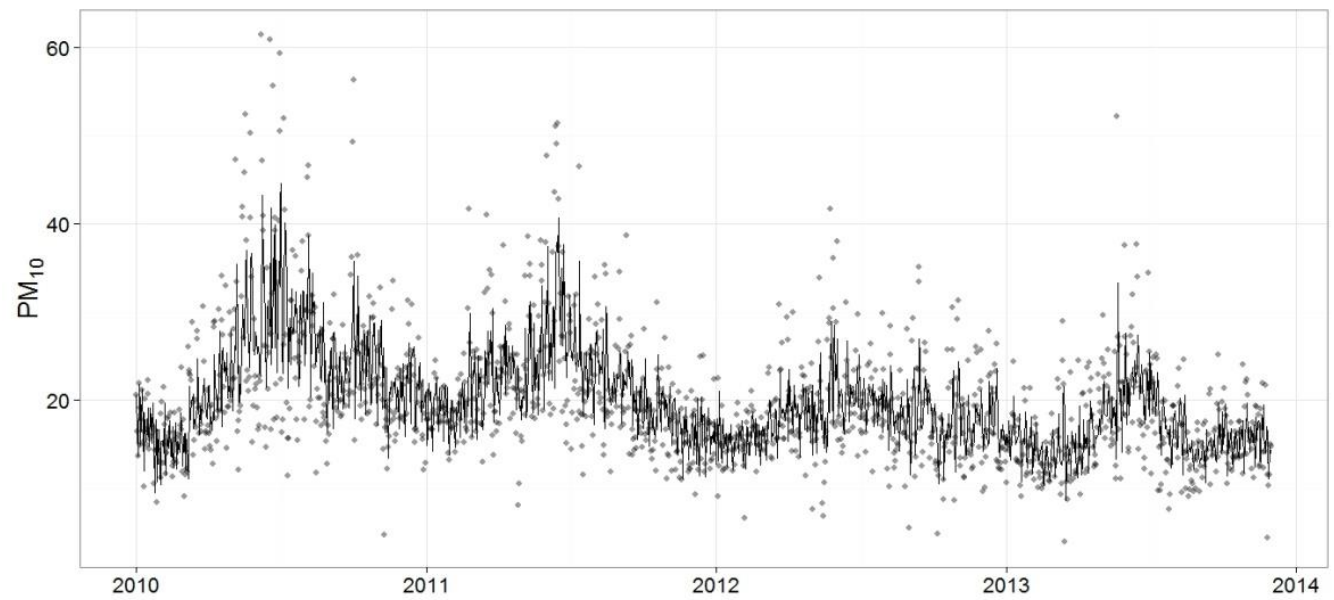

Figura 2: Ajuste do modelo SARIMA $(1,1,2)(1,1,2) 7$ (---------) série temporal das concentrações de material particulado $\mathrm{PM}_{10}$ na região de Carapina/ES/Brasil.

Assim como comprovação da assertividade do modelo, foram construídos gráficos de ACF e PACF (Figura 3). Os resíduos do modelo não apresentam autocorrelação.

O valor da correlação do lag5 apresentou uma pequena autocorrelação, porém sem efeito significativo conforme o teste de Ljung-Box test ( $p$ valor $=0.2387$ ). A tabela 1 mostra as previsões do modelo para 10 dias. Os resultados da Tabela 1 indicam uma previsão de qualidade do modelo propostos. 

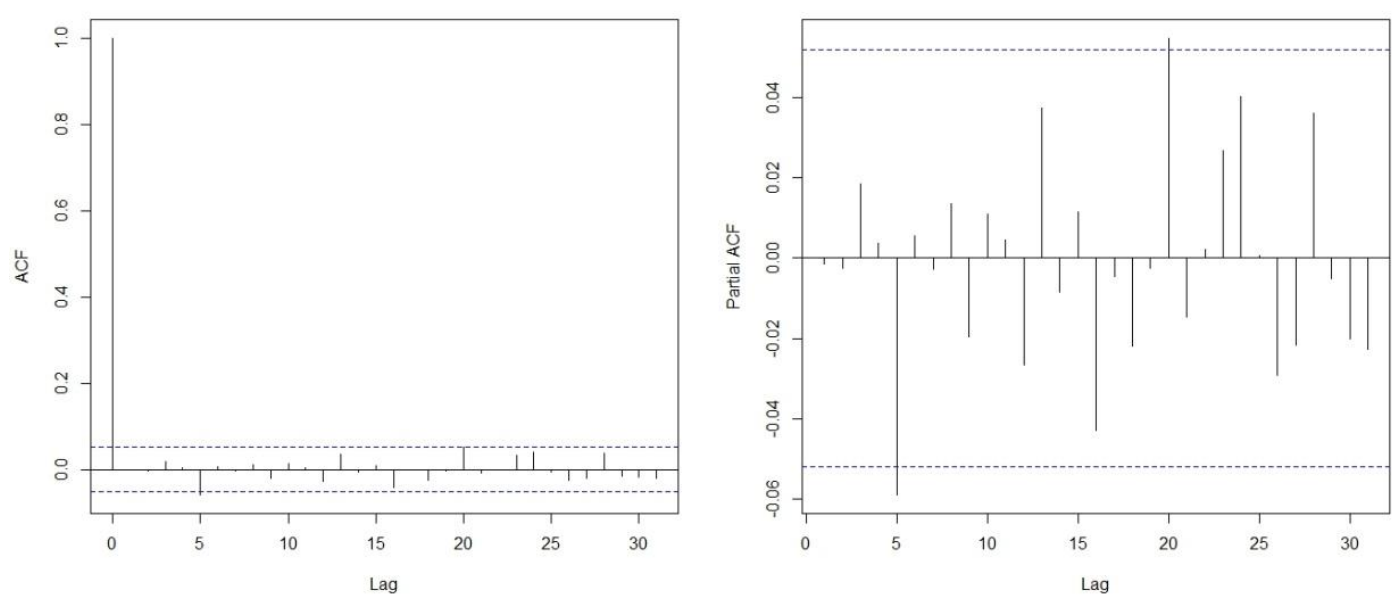

Figura 3: ACF e PACF dos resíduos do modelo SARIMA $(1,1,2)(1,1,2) 7$, com um limite de significância 0,05 .

Tabela 1: Previsão do modelo SARIMA $(1,1,2)(1,1,2) 7$ para as concentrações de material particulado $\mathrm{PM}_{10}$ no período de 01/01/2013 a 10/01/2013.

\begin{tabular}{lcr}
\hline SARIMA $(1,1,2)(1,1,2) 7$ & Previsto & Observado \\
\hline $01 / 12 / 2013$ & & 14,71 \\
$02 / 12 / 2013$ & 12,84 & 13,75 \\
$03 / 12 / 2013$ & 14,66 & 19,13 \\
$04 / 12 / 2013$ & 14,64 & 14,83 \\
$05 / 12 / 2013$ & 15,44 & 15,33 \\
$06 / 12 / 2013$ & 15,74 & 14,17 \\
$07 / 12 / 2013$ & 15,47 & 14,29 \\
$08 / 12 / 2013$ & 13,57 & 12,39 \\
$09 / 12 / 2013$ & 12,68 & 12,42 \\
$10 / 12 / 2013$ & 14,82 & 15,54
\end{tabular}

\section{Conclusão}

Estes resultados indicam que os modelos de séries temporais propiciam uma melhor compreensão da dinâmica das concentrações de material particulado emitido diariamente nos grandes centros urbanos, principalmente na região estudada. Espera-se que os resultados alcançados possam auxiliar nos programas de saúde pública e de meio ambiente.

\section{Agradecimentos}

Os autores agradecem a FAPES pelo apoio financeiro.

\section{Referências}

[1] BAKONYI, S. M. C.; OLIVEIRA, I. M. D.; MARTINS; L.C.; BRAGA, F. L. A., Poluição atmosférica e doenças respiratórias em crianças na cidade de Curitiba, PR, Revista de Saúde Pública, v. 38, p. 695-700.

[2] DOCKERY, D. W.; POPE, C.A. Acute respiratory effects of particulate air pollution, v. 15, p. 107-132, 1994.

[3] SCHWARTZ, J., Harvesting and long term exposure effects in the relationship between air pollutions and mortality. American Journal Epidemiologic, v. 151, p. 440-448, 2000.

[4] CLYDE, M., Model uncertainty and health effect studies for particulate matter. Environmetrics, v.11, 745-763., 2000.

[5] IBAMA. Resoluções CONAMA, 1984/91, 1992. 4a. ed. rev. e aum, Brasília. 